\title{
Intervención psicopedagógica en niños Maltratados: Estimulación del lenguaje.
}

\author{
Juan Manuel Moreno Manso ${ }^{1}$ \\ $M^{a}$ José Rabazo Méndez ${ }^{1}$
}

${ }^{1}$ Dpto. de Psicología y Sociología de la Educación, Universidad de Extremadura, Badajoz

\section{España}

althea@correo.cop.es 
Intervención psicopedagógica en niños maltratados. Estimulación del lenguaje. 


\section{Resumen}

Introducción. En el artículo proponemos un programa de intervención dirigido a la estimulación del lenguaje oral y diseñado para ser aplicado a niños que han sido objeto de maltrato infantil y se encuentran institucionalizados en centros de acogida de menores. Diferentes estudios realizados destacan las dificultades del niño maltratado en el plano verbal y en las diferentes áreas del desarrollo.

Método. La muestra a partir de la cual se diseña el programa de intervención se compone de veinte niños en situación de maltrato infantil, de edades comprendidas entre los 5 y 9 años. La evaluación del desarrollo lingüístico de los niños fue realizada mediante la Batería de Lenguaje Objetiva y Criterial, BLOC (Puyuelo, Wiig, Renom y Solanas, 1998).

Resultados. Los resultados indican baja autoestima y escasa habilidades comunicativas y de relación social. Los niños muestran dificultad para adaptar el lenguaje al contexto y utilizan un vocabulario muy reducido que dificulta la comprensión de contenidos. Se evidencia que hay un retraso importante en los diferentes aspectos del lenguaje evaluados. Especialmente llaman la atención las marcadas dificultades de pragmática.

Discusión. La investigación destaca la necesidad de poner en marcha programas de intervención que incidan en la competencia personal, lingüística y social de menores que han sido objeto de situaciones de maltrato infantil. En estos niños es fundamental el desarrollo de habilidades o competencias que promuevan el funcionamiento social adaptativo, habilidades básicas para la interacción social que favorezcan la función pragmática del lenguaje, habilidades para relacionarse con adultos y para la solución de problemas interpersonales.

Palabras Clave: maltrato infantil, lenguaje, intervención, investigación. 


\section{Introducción}

A continuación describimos un programa de intervención dirigido a la estimulación del lenguaje oral y diseñado para ser aplicado a niños que han sido objeto de maltrato infantil y se encuentran institucionalizados en centros de acogida de menores (C.A.M.). Previamente, analizamos cuáles son los componentes lingüísticos en los cuales los niños manifiestan mayor dificultad.

El objetivo de un centro de acogida es acoger temporalmente a niños/as y jóvenes que se encuentran en situaciones de riesgo social o desamparo (Ley Orgánica 21/1987, de 11 de Noviembre, por la que se modifican determinados artículos del Código Civil y de la Ley de Enjuiciamiento Civil en materia de Adopción) y proporcionar una atención integral a aquellos menores que por determinadas circunstancias no puedan recibirla de sus familiares.

La Ley Orgánica 21/1987, delimita cuáles son las situaciones de desprotección objeto de institucionalización del menor: situaciones que se producen por el imposible ejercicio de los deberes de protección, circunstancias del niño (fallecimiento de padres, prisión, enfermedades incapacitantes, etc.) que hacen que éste no reciba ni cuidados ni atención; situaciones que se producen por el incumplimiento de los deberes de protección, en las que los responsables del niño renuncian total y absolutamente a cumplir sus deberes de protección (renuncian a la paternidad, lo abandonan a terceros o lo dejan solo, en completa desatención); y situaciones que se producen por un inadecuado cumplimiento de los deberes de protección, tales como el maltrato físico, maltrato emocional, abandono físico, abandono emocional, abuso sexual, etc.

La mayor parte de los niños institucionalizados en centros de acogida han sufrido alguna situación de desprotección que en mayor o menor medida ha mermado su desarrollo físico, social, lingüístico, afectivo o cognitivo. Los menores carenciales acogidos en un centro de protección, por lo general, han experimentado muchas decepciones y han vivido en conflicto continuo, ya que no han podido manifestar sus impulsos y expresarse en su medio de un modo espontáneo y armónico en la mayoría de las ocasiones. Esto ha motivado la intervención de las autoridades y la puesta en marcha de una acción educadora urgente que restituya, en la medida de lo posible, el derecho a crecer en un ámbito que satisfaga sus necesidades materiales y psicológicas. 
Todo niño necesita del trato confiado y frecuente por parte de algún familiar para el desarrollo normal y armónico, siendo ésta la razón principal del internamiento de muchos niños. Los niños criados en un clima ausente de afecto son propensos a desarrollar ciertos rasgos patológicos, tales como retrasos globales en el desarrollo y dificultades en el plano relacional.

Fuertes y Fernández (1996) mantienen que algunos de los objetivos prioritarios para el trabajo con menores institucionalizados en centros de acogida deben ir orientados al desarrollo de habilidades lingüísticas (conocimiento y expresión de vocabulario, lectoescritura,...), habilidades sociales (establecimiento de relaciones, manejo de situaciones sociales, empatía, participación en grupo,...), desarrollo afectivo, emocional y motivacional (autoestima, autocontrol, expresión de sentimientos, vinculaciones afectivas,...)...

Asimismo, diferentes autores señalan que los trastornos en el establecimiento de la relación de apego constituyen la causa de muchas de las dificultades que manifiestan los niños objeto de maltrato infantil. De ahí la importancia de poner en marcha programas que favorezcan las habilidades de comunicación en los niños y fomenten la expresión abierta de los propios sentimientos a través del lenguaje.

El programa de intervención que proponemos permite entrenar el desarrollo lingüístico del menor, mientras dura la institucionalización, y proporcionar un mejor asesoramiento y orientación a las familias que reciben a estos niños en acogimiento o adopción, facilitando asimismo la integración del niño en el entorno familiar (a fin de conseguir un desarrollo armónico de su personalidad y una correcta atención de las necesidades psicológicas y materiales del menor). El análisis de las dificultades en el desarrollo de niños en situación de desprotección nos permitirá la búsqueda de alternativas idóneas e individualizadas a cada uno de estos niños y facilitara el seguimiento del niño en el entorno familiar (proporcionando apoyos concretos en caso de necesidad).

Numerosos estudios realizados (Tizard, Cooperman, Joseph y Tizard, 1972; Bousha y Twentyman, 1984; Rutter y Lord, 1987; Martínez y De Paúl, 1993; Urquiza y Winn, 1994; Gaudin, Polansky, Kilpatrick y Shilton, 1996; Moreno, 2003; Moreno, 2005) destacan las dificultades del niño maltratado en el plano verbal y en las diferentes áreas del desarrollo. Algunas de las principales consecuencias son las siguientes: deficiencias importantes en la adquisición y el desarrollo del lenguaje, dificultades en aplicación correcta del lenguaje común de uso, incapacidad para abstraer y generalizar los conceptos, vocabulario pobre, redu- 
cido y redundante, dificultad en la comprensión de nociones abstractas, escaso lenguaje espontáneo, construcciones gramaticales reiteradas y ausentes de nexos, imprecisiones articulatorias, dificultad para relacionarse con otros (incompetencia en el funcionamiento social), reacciones de agresividad verbal, atención fluctuante, dispersa, inconstante y débil, limitado razonamiento lógico, lateralidad mal definida confundiendo derecha - izquierda y la posición de los objetos entre sí y con referencia al sujeto, lo cual deriva en realizaciones gráficas y psicomotrices con una deficiente orientación y confusión espacial y temporal, inadecuación de figuras imitativas y una falta de identidad personal, pobreza de reacciones estimulares y perturbaciones anímicas (sintomatología depresiva), inseguridad, desvalorización y baja autoestima, actitudes defensivas, etc.

\section{Método}

\section{Participantes}

La muestra a partir de la cual se diseña el programa de intervención se compone de veinte niños en situación de maltrato infantil, de edades comprendidas entre los 5 y 9 años. La valoración de la situación de desprotección de los menores ha sido realizada por los Servicios Sociales, utilizando para ello los criterios operativos del Programa para la mejora del Sistema de Atención Social a la Infancia (SASI) del Ministerio de Trabajo y Asuntos Sociales, para la detección, notificación, investigación y evaluación de situaciones de maltrato infantil (Arruabarrena, De Paúl y Torres, 1996).

\section{Instrumentos}

Los instrumentos utilizados para la evaluación del desarrollo lingüístico de los niños (conocimientos del lenguaje y componentes deficitarios), teniendo en cuenta la edad de los menores, han sido la Batería de Lenguaje Objetiva y Criterial BLOC-Screening (Puyuelo, Renom, Solanas y Wiig, 2002) y la versión completa BLOC - C (Puyuelo, Wiig, Renom y Solanas, 1998).

\section{Procedimiento}

El procedimiento ha consistido en la aplicación de la versión Screening de la Batería de Lenguaje Objetiva y Criterial (BLOC), destinada a detectar si existen dificultades en algu- 
no de los cuatro componentes del lenguaje (morfología, sintaxis, semántica y pragmática). Esta prueba nos permite estimar el riesgo de que exista problema del lenguaje en cada una de las 4 habilidades comunicativas evaluadas. También nos informa de forma global del nivel lingüístico y comunicativo del niño en los 4 módulos, reduce considerablemente el tiempo de aplicación respecto a otras pruebas y nos indica qué modulo de la batería completa BLOC-C debemos administrar al niño al completo para obtener más datos y una puntuación más exacta.

La Batería de Lenguaje Objetiva y Criterial, es de aplicación a partir de los 5 años. Esta prueba nos permite evaluar la expresión y la comprensión de niños en los cuatro componentes del lenguaje, cuantitativa y cualitativamente. Es muy útil para el diseño de planes de intervención individualizados y grupales.

El módulo de morfología evalúa el uso de plurales, formas verbales regulares e irregulares, reflexivos, posesivos, etc. El módulo de sintaxis explora la estructura de la oración, el sintagma nominal, el sintagma verbal, el sintagma adjetivo, el objeto directo, el objeto indirecto, etc. El módulo de semántica evalúa el conocimiento que tiene el niño de la función significativa de ciertos elementos de la oración: agente, paciente, instrumental, nociones cualitativas y de cantidad, etc. Y el módulo de pragmática estudia el uso del lenguaje en diferentes contextos comunicativos.

A lo largo de los 4 módulos, las tareas a llevar a cabo para provocar la respuesta del niño son las siguientes: denominar dibujos (objetos o acciones), completar frases orales incompletas (generalmente en respuesta a dibujos), producción paralela (formular frases que, a nivel de estructura son similares a las que le propone el evaluador, también en respuesta a dibujos) y lenguaje inducido (el niño debe expresar verbalmente una respuesta ante situaciones que le presentamos en un dibujo).

\section{Resultados}

La aplicación del BLOC (screening y completa) evidencia la presencia de dificultades relevantes en morfología y pragmática. Los niños muestran un escaso dominio de estas dos habilidades lingüísticas. Las puntuaciones de los menores se sitúan entre los centiles 30 y 60 . El nivel de dominio de las diferentes habilidades psicolingüísticas se sitúa en el 70\%. Los resultados indican puntuaciones inferiores al porcentaje mencionado. 
Tabla 1. Medias y Desviaciones Típicas de la Batería de Lenguaje Objetiva y Criterial

\begin{tabular}{|c|c|c|c|c|c|}
\hline BLOC-S & & Morfología & Sintaxis & Semántica & Pragmática \\
\hline & $\mathrm{X}$ & 3,00 & 2,49 & 2,38 & 3,17 \\
\hline & $\mathrm{Sx}$ &, 93 & 1,02 &, 77 &, 60 \\
\hline
\end{tabular}

$1=$ superior (Centil 70-100) $2=$ transición (Centil 60-70) $3=$ emergencia (Centil 30-60) $4=$ alarma (Centil inferior 25-30)

Los resultados indican baja autoestima y escasa habilidades comunicativas y de relación social. Los niños muestran dificultad para adaptar el lenguaje al contexto y utilizan un vocabulario muy reducido que dificulta la comprensión de contenidos. De ahí que en el módulo de morfología se constaten dificultades en la comprensión de los enunciados que contienen las palabras a partir de las cuales se deben configurar las respuestas. En morfología, los niños muestran dificultad para utilizar las formas verbales irregulares pasadas y futuras, utilizan pocos adjetivos, adverbios y conjunciones, muestran dificultad con las formas complejas de los verbos, en los pronombres personales de tercera persona y en el uso del concepto de posesión.

Se evidencia que hay un retraso importante en los diferentes aspectos del lenguaje evaluados por los cuatro módulos. Especialmente llaman la atención las marcadas dificultades de pragmática. En pragmática, destacamos un escaso nivel de dominio de los niños. Los resultados indican la dificultad de los menores para reclamar atención, para realizar demandas de información específicas, para el uso de pronombres interrogativos, el uso del adverbio interrogativo de lugar "dónde" y el adverbio interrogativo de tiempo "cuándo". Asimismo, también debemos resaltar las dificultades en el uso del "de quién”, "para quién” y "a quién”, en el uso del "por qué" / "cómo" o "de qué manera" y los requerimientos directos e indirectos de acción. Los niños tienen dificultad para dar respuesta cuando el enunciado les resulta demasiado largo, no logran mantener la atención y comprensión durante todo el tiempo y les faltan recursos para responder ante determinadas situaciones. Los niños son parcos en palabras, en ocasiones saltan de unos temas a otros, les cuesta ponerse en el lugar de adultos e imaginar lo que dirán, dificultad para pedir algo como favor, sobre todo en aquellas situaciones en las que el niño representado en las escenas pide a su madre u otro adulto algún objeto. Tienen dificultad para solicitar más información sobre algún acontecimiento o para aclarar aspectos, para mostrar desagrado o disgusto acerca de algo, para formular demandas explícitas, para reque- 
rimientos indirectos de acción, limitaciones tanto para expresar cómo para mostrar desacuerdo con niños y adultos, tendencia a realizar grandes rodeos, escasa habilidad para mostrar desacuerdo ante una figura de autoridad: padre, madre, profesora.. Estos resultados pueden relacionarse en cierta medida con los de Dodge, Bates y Pettit (1994). Según estos autores, los niños que han sido objeto de situaciones de desprotección durante la infancia, carecen de estrategias competentes en la solución de problemas interpersonales.

En relación a la sintaxis, los niños utilizan construcciones muy breves, predominando las oraciones simples, la capacidad para realizar una determinada estructura lingüística a partir de un enunciado no es la adecuada, los niños manifiestan dificultades para utilizar la forma pasiva, oraciones más complejas como las subordinadas causales, temporales, adversativas y de relativo.

Y por último, en semántica los resultados no son tan bajos, aunque los niños tienen dificultad para utilizar el dativo, la noción de cantidad con adverbios cuantificadores y pronombres y la comprensión y el uso de los modificadores de tiempo y sucesión

\section{Implementación del programa de intervención}

A partir de los resultados de la aplicación de la Batería del Lenguaje Objetiva y Criterial (BLOC) nos planteamos los siguientes objetivos de cara a la intervención con los menores.

En primer lugar, mejorar la expresión y comprensión de los niños a través de un programa de estimulación lingüística, siguiendo las pautas del proceso normal de adquisición del lenguaje y a través de procesos de imitación y modelado; y en segundo lugar, nos planteamos la necesidad de favorecer el desarrollo emocional y afectivo de los menores.

Durante todas las sesiones se trabajaron los cuatro niveles del lenguaje (morfología, sintaxis, semántica y pragmática) a través de diferentes tareas y actividades. La propuesta metodológica se centró en la estimulación, reorganización y reestructuración del lenguaje de los niños. En todo momento la intervención tuvo un carácter cooperativo, potenciando la colaboración de los tutores de los niños y la familia.

Intentamos, en la medida de lo posible, ajustar la intervención a la individualidad de cada niño, secuenciando y seleccionando los contenidos a aprender por cada uno de ellos según el enfoque del desarrollo y priorizando sobre el enfoque comunicativo (funcional e in- 
teractivo). De ahí que en todo momento, la enseñanza de las habilidades tuviera una función social.

Asimismo, la intervención fue dirigida sobre aspectos del desarrollo de los niños relacionados directamente con su lenguaje (procedimiento) y con los déficits lingüísticos observados (código).

A nivel de procedimiento, trabajamos la capacidad de atención, motivación, percepción y discriminación, imitación, memoria, coordinación motora, organización del esquema corporal, desarrollo espacio-temporal y ritmo. Y a nivel de código, la reeducación semántica, morfología, sintaxis, semántica y pragmática. Fue imprescindible la evaluación continuada del proceso reeducador.

Para facilitar la lectura y no repetir el contenido de algunas de las sesiones hemos seleccionado los objetivos y las tareas que utilizamos para mejorar el desarrollo del lenguaje oral de los niños atendiendo a las diferentes dimensiones que formaron parte del proceso de intervención:

1. Mejorar la expresión y comprensión de los niños a través de un programa de estimulación lingüística.

\section{A) Morfosintaxis.}

Objetivos:

a Facilitar la estructuración de enunciados siguiendo el desarrollo evolutivo normal.

a Comenzar consolidando las reglas gramaticales que ya conoce.

Enseñarles estructuras gramaticales útiles y funcionales para los niños.

\ Empezar con estructuras gramaticales más fáciles de demostrar y comprender por los niños

- Practicar cada estructura gramatical aprendida con diferentes elementos lexicales y en diferentes contextos.

a Potenciar la comprensión de estructuras gramaticales (de oraciones simples a complejas). 
Actividades (mediante tareas de imitación y modelado):

$\checkmark$ Los niños repiten frases de menor a mayor complejidad (p. ej.: "el grifo gotea"; "Subí corriendo a su casa y llamé al timbre").

$\checkmark$ Los niños ante una frase dada, señalan la imagen que mejor lo representa (p. ej.: TSA. Aguado, 2000). Les mostramos una lámina compuesta por 4 dibujos y les pedimos que identifiquen el dibujo que corresponde a la frase que el terapeuta le dice.

$\checkmark$ Los niños deben repetir la frase que se adecua con el dibujo que el terapeuta señala. Mostramos a los niños láminas con dos dibujos mientras decimos dos frases (seguidas) que los identifican. A continuación, el terapeuta señala cada uno de los dibujos y los niños deben repetir la frase que los identifica.

$\checkmark$ Los niños completan frases de menor a mayor complejidad. El terapeuta inicia frases que los niños debe acabar, utilizando distintas formas verbales (presente de indicativo, potencial, imperativo, subjuntivo, presente subjuntivo, imperativo subjuntivo, etc.).

$\checkmark$ Los niños completan frases apoyadas en dibujos, utilizando determinadas estructuras gramaticales (p. ej.: Este niño va detrás. Estos otros van.........(delante)).

$\checkmark$ Los niños construyen frases que le sugieren imágenes proporcionadas por el terapeuta.

$\checkmark$ Los niños construyen frases siguiendo las técnicas de incrementación: "el niño come....." "el niño come pan"; "María va....." "María va al colegio con su amiga".

$\checkmark$ Los niños en sus respuestas va ampliando la estructura. El terapeuta facilita la expansión verbal mediante preguntas del tipo: qué está haciendo, con qué, por qué, por dónde, cuándo, etc.

$\checkmark$ Los niños construyen frases siguiendo las técnicas de sustitución de elementos: "Marta coge un...........de su mochila", "la tortuga........muy despacio".

$\checkmark$ Los niños identifican frases incorrectas dichas por el terapeuta (en cuanto a la forma) y las formulan correctamente: “Los pájaros vuela...¿por qué está mal?”; “Ayer vamos al cine"; "Juan cogió una pelota que eran redondas", etc.

$\checkmark$ Los niños identifican el enunciado correcto entre varios que se le proporcionan.

$\checkmark$ Los niños formulan preguntas a respuestas dadas (ej., Son las cinco y cuarto; ¿Qué hora es?). 
$\checkmark$ Formulamos preguntas directas a los niños cuyas respuestas obligan el uso de determinadas formas gramaticales que omiten.

$\checkmark$ Los niños formulan oraciones subordinadas temporales, causales, de relativo y condicionales, a partir de las preguntas que le formula el terapeuta. Oraciones adverbiales de tiempo (p. ej.: Ana se irá a jugar después de merendar. ¿Cuándo se irá Ana a jugar? El niño debe responder "después"). Oraciones causales (p. ej.: Pedro estaba jugando. Se tropezó con una piedra y se cayó. ¿Por qué se cayó Pedro? El niño deber responder "porque"). Oraciones de relativo (p. ej.: La pelota que me regaló mi tía se ha roto. ¿Qué pelota se ha roto?. El niño debe responder "la que"). Oraciones condicionales (Si comes te daré un beso" "Te daré un beso. (si comes)).

$\checkmark$ Los niños y el terapeuta conversan en torno a hechos ocurridos en distintos momentos temporales: presente, pasado y futuro. Utilizamos tarjetas y viñetas que representan acontecimientos cotidianos, las ordena respetando la secuencia temporal, de este modo incidiremos en los conceptos de pasado, presente y futuro.

$\checkmark$ Los niños realizan frases según un modelo correcto dado (p. ej.: BLOC. Puyuelo y cols., 1998):

- Formas verbales irregulares: Los niños deben completar frases usando la forma pasada. (p. ej.: El padre de Sofía sabe que ella suele querer salchichas. Ayer por la noche (ella) (quiso salchichas)).

- Formas verbales irregulares: Los niños deben completar frases usando la forma futura. (p. ej.: El padre de Sofía sabe que para cenar ella suele querer salchichas. Mañana para cenar (ella). (querrá salchichas)).

- Sustantivos derivados. Los niños deben formar palabras nuevas derivándolas del verbo, del sustantivo o del adjetivo, y para ello tienen que utilizar sufijos derivativos transformadores (p. ej.: Esta chica va a nadar cada día. Al deporte de nadar se le llama........ (natación); Estos chicos están agotados de tanto correr. Han tenido que parar debido al (agotamiento).

○ Pronombres personales: Los niños deben completar frases utilizando sujetos $\left(1^{\mathrm{a}}, 2^{\mathrm{a}}\right.$ y $3^{\mathrm{a}}$ persona: yo, tú, él, ella, nosotros, vosotros, ellas). (p. ej.: Estos niños han cogido una rana y la han guardado en una caja. El profesor abre la caja y cuando ve la rana pregunta: ¿Quién ha puesto una rana en esta caja? Los niños responden (nosotros)). 
- Pronombres personales en función de objeto (pronombres átonos de $3^{a}$ persona: el/ella; cuando es objeto directo son: lo/s y la/s; y cuando es objeto indirecto: le/s, convirtiéndose en "se" cuando lleva puesto lo/s o la/s. (p.ej.: Observa este dibujo. Las chicas plantan flores. Sustituye "flores" por otra palabra. Las chicas (las plantan)).

- Reflexivos (pronombres reflexivos y recíprocos y otros pronombres átonos que siempre acompañan a un verbo: se, me, te, nos, os,). (p. ej.: Observa este dibujo. Estos dos niños no quieren que les encuentren. Si les preguntamos: ¿Qué hacéis?, ellos nos dirán. (nos escondemos)).

- Posesivos. Evalúa las nociones de posesión: mío, tuyo, suyo, nuestro, vuestro. (p. ej.: Este señor enseña los perros a los niños. Los perros son de él. El señor dice a los niños: Estos perros son (míos)).

- Voz pasiva (el sujeto no concuerda con el agente de la oración porque la acción recae sobre él). (p. ej.: El niño persigue al perro. Explícamelo empezando con: "El perro" (el perro es perseguido por el niño)).

○ Oraciones subordinadas. Causa y condición. (p.ej.: Mira al chico de estos dibujos. Dime qué hizo y la razón de ello (el chico se puso los patines porque quería patinar / para poder patinar).

- Subordinadas temporales: después / antes. (p. ej.: Mira lo que ocurre en este dibujo. ¿Puedes explicarme lo que hace el niño en una sola frase? Empieza con “después” (después de lavar la manzana, el niño se la come)).

○ Subordinadas temporales: cuando / hasta que. (p. ej.: Estos niños quieren nadar, pero están limpiando la piscina. ¿Puedes decirme ambas cosas en una sola frase? Usa la palabra "cuando" (los niños podrán nadar cuando hayan limpiado la piscina)).

○ Subordinadas adversativas (aunque, pero). (p. ej.: Es el cumpleaños de este niño. Él quería un perrito. Sin embargo, sus padres le han regalado un gatito. ¿Puedes explicarme las dos cosas que ocurren en una frase, utilizando la palabra "pero"? (el niño quería un perrito, pero le han regalado un gatito). 
○ Subordinadas de relativo (que). (p. ej.: Veo un perro que duerme cerca de un arbusto. Dime qué ves. Empieza con "Veo........." (veo un gato que duerme bajo un árbol).

\section{B) Semántica.}

Objetivos:

- Enseñar a los niños léxico (nombres, adjetivos, preposiciones, verbos de acción, fórmulas de interacción social), partiendo de lo que la niña conoce.

\section{Actividades:}

$\checkmark$ Los niños nombran objetos (que hay en casa, en el colegio, en el parque, en la cocina, etc.) y sus características.

$\checkmark$ Los niños establecen semejanzas y diferencias. Los niños deben establecer semejanzas entre diferentes objetos de uso común. Se le preguntan cuestiones tales como: ¿En qué se parecen una rueda y una pelota?, ¿En qué se parecen una vela y una lámpara?

$\checkmark$ Los niños clasifican palabras según un criterio dado: analogías (Ej: azul es al cielo, como verde es a la hierba).

$\checkmark$ Los niños deben definir palabras por el uso. Ejemplo: "qué quiere decir la palabra: (martillo, bufanda, cocinar, hablar, bello, alegre)" "para qué sirve el jabón”.

$\checkmark$ A los niños se les presentan varias tarjetas con dibujos, para que las ordenen y nos cuenten con ellas una historia con sentido.

$\checkmark$ A los niños les presentamos un conjunto de dibujos sobre los cuales el terapeuta lee en voz alta unas frases que los describen brevemente. Los niños deben señalar las frases que se refieren a un determinado concepto. Los conceptos utilizados son espaciales, temporales y de cantidad (arriba, a través, lejos, junto a, dentro, más cerca, detrás, siempre, debajo, ni primero ni último, varios, etc.).

$\checkmark$ Los niños relacionan conceptos que se presentan oralmente. Los niños deben manejar símbolos lingüísticos de manera significativa mediante una serie de analogías verbales de dificultad creciente. Por ejemplo: El papá es grande, el niño es. 
Los niños deben describir las características de una persona, describir su ropa, etc. Decir palabras que empiezan por una misma letra, etc.

$\checkmark$ Buscar sinónimos y antónimos. Los niños expresan palabras de significado contrario a otras dadas:"El caracol no es rápido, el caracol es ..,;"La esponja no es dura, la esponja es ..

$\checkmark$ Los niños realizan frases según un modelo correcto dado (p. ej.: BLOC. Puyuelo y cols., 1998):

○ Dativo: Los niños deben completar oraciones diciendo el dativo. (p. ej.: Éste es David. Él ha terminado sus deberes. ¿Qué hace con ellos? El los entrega........... (a su profesora)).

- Locativo: Los niños deben completar oraciones utilizando diferentes conceptos de localización (dentro, en, sobre, encima, delante, detrás, debajo, en medio de, junto, dentro, fuera,... (p. ej.: Mino es un gato que está durmiendo. ¿Dónde duerme Mino? (dentro de / en la cesta)).

- Cuantificadores: Los niños deben completar frases utilizando nociones de cantidad con adverbios cuantificadores (mucho, poco) y pronombres (todo, nada) (p. ej.: En la toalla de esta chica hay arena. ¿Cuánta arena hay? (mucha / bastante)).

- Modificadores de tiempo y sucesión: Los niños deben completar frases usando términos de temporalidad (ayer, mañana) y de espacialidad en el tiempo (después, antes, primero). (p. ej.: ¿En qué lugar de la fila está el gato? (el primero) o ¿Cuándo ha llegado Juan a la escuela? (temprano / pronto)).

\section{C) Pragmática.}

\section{Objetivos:}

口 Desarrollar habilidades funcionales que les permitan una comunicación efectiva.

- Fomentar la iniciativa y la espontaneidad en la conversación.

- Potenciar el establecimiento de turnos a través de actividades de interacción verbales y no verbales (mediante pausas por parte del terapeuta y señales verbales y no verbales).

- Introducir eficazmente temas nuevos de conversación. 
- Incorporar los recursos lingüísticos trabajados a contextos naturales.

口 Practicar habilidades sociales.

- Eliminar la jerga, muletillas, circunloquios, ecolalia, y ecolalia demorada que observamos en los niños. Para ello, recomendamos dirigir su lenguaje: que repitan las palabras con el evaluador, que hablen más lentamente y que verbalicen lo que hacen ante tareas concretas, etc.

\section{Actividades:}

$\checkmark$ A través de dramatizaciones de cuentos o de situaciones de la vida real (llama por teléfono para quedar con un amigo, va a comprar y pide algo, etc.), en la que los niños asumen distintos roles y verbaliza sentimientos, emociones, ... Los niños deben aprender a seguir el ritmo de una conversación y a interactuar verbalmente con los otros.

$\checkmark$ Simular situaciones donde los niños deben saludar y despedirse con la entonación correspondiente.

$\checkmark$ Nosotros contamos a los niños durante un minuto todo lo que hemos visto por la mañana antes de llegar al colegio, y los niños deben hacer lo mismo.

$\checkmark$ Eliminamos el texto de las viñetas de cómic. Terapeuta y niños deben rellenar el contenido de las viñetas (interacción comunicativa entre los personajes).

$\checkmark$ Comprensión y adaptación. Los niños deben resolver verbalmente situaciones que pueden darse en su vida cotidiana. "¿Qué debes hacer si te das cuenta que vas a llegar tarde a la escuela?”- “QQué debes hacer si tienes que cruzar la carretera?”.

$\checkmark$ Planificación. Los niños deben planificar verbalmente un juego conocido. ¿Sabes jugar al escondite? Explícame cómo se juega al escondite.

$\checkmark$ Juego de los indicios (juego del veo veo). El terapeuta debe averiguar el nombre de la persona o cosa de la cual los niños van dando pistas.

$\checkmark$ Pedir a los niños que narren todos los pasos o acciones que realiza desde que se levantan hasta que se acuestan. Pedir a los niños que narren todos los pasos o acciones que realiza.

$\checkmark$ Por medio de imágenes, pedimos a los niños que nos describan todo aquello que ven. 
Los niños deben ordenar y relatar una historieta de varias secuencias, superando la mera yuxtaposición de explicaciones.

$\checkmark$ A los niños se le presentan imágenes contextuales. Los niños deben proyectar las experiencias y los sentimientos de los demás, sus reacciones ante situaciones concretas (deben ponerse en la piel del otro).

$\checkmark$ Plantear situaciones, problemas o acontecimientos de la vida diaria con la finalidad de que los niños expliquen cuáles serían sus reacciones, cómo actuarían.

\section{Favorecer el desarrollo emocional y afectivo de los niños.}

Dentro del programa trabajamos actividades destinadas a que los niños desarrollen su afectividad:

- Aprendan a comunicar los sentimientos verbalmente (según el tono de voz y el movimiento) o de forma no verbal.

Reconozcan e identifiquen los sentimientos en los demás.

\ Expresen e identifiquen los sentimientos de forma verbal o por medio de gestos y posturas, y se hacen conscientes del clima emocional que se crea con ello.

a Identifiquen sentimientos a través de expresiones faciales.

- Aprendan a identificar las causas de algunos sentimientos y sus consecuencias.

․ Representen sentimientos por medio de role-playing.

- Aprendan a comprender cómo influyen los sentimientos en la conducta de las personas.

- Aprendan a verbalizar y representar sentimientos en diversas situaciones a través de role-playing (facilita la expresión oral).

a Aprendan a hacerse conscientes de los sentimientos y necesidades de los otros.

- Aprendan a participar conjuntamente en una actividad común. Participar por turnos.

a Aprendan a prestar la máxima atención cuando se escucha. 
Dada la situación de desprotección de los niños, decidimos intervenir sobre los padres mediante un "entrenamiento parental en habilidades para el manejo de la comunicación e interacción con los niños":

- Consistencia verbal y no verbal en las interacciones con los niños.

a Comunicación clara y directa entre los miembros de la unidad familiar.

a Correspondencia en la comunicación.

- Expresividad.

- Claridad en la forma y en la sintaxis, así como en el pensamiento abstracto y metafórico.

- Aumentar la frecuencia de las interacciones con los niños.

- Expresión de sentimientos hacia los niños consistente y estable.

a Potenciar las conductas verbales y físicas positivas y disminuir las negativas.

a Entrenar en habilidades verbales y no verbales de comunicación con los niños.

․ Enseñar habilidades para la estimulación de los menores.

a Proporcionar habilidades para la demostración de afecto hacia los niños.

Para ello utilizamos materiales audiovisuales y escritos sencillos de comprender. Nuestro objetivo es transmitirles conocimientos y enseñarles habilidades (finalidad educativa). Los padres deben tomar conciencia de que no sólo ellos tienen problemas personales y familiares y deben aprender a compartir sus sentimientos, descubriendo que tienen cualidades y habilidades para el cuidado y la estimulación de sus hijos.

Preparamos a los padres para que comprendan los objetivos y las motivaciones del comportamiento infantil, les ayudamos a comprenderse mejor a sí mismos (por qué reaccionan de una determinada manera ante una situación, cuál es su reacción, etc.), y les enseñamos la habilidad de estimular a los hijos.

Se trabajan situaciones que tienen la finalidad de ayudar a los padres a comprender el concepto de la estimulación y su proceso de aplicación, y se enfatiza la comunicación: cómo escuchar y cómo comunicar a los niños los sentimientos, sin amenazarlos. 
Con los padres utilizamos técnicas de discusión de material escrito y audiovisual, de modelado y role-playing, cognitivas (reestructuración), de autocontrol emocional (detención del pensamiento, técnicas de afrontamiento y entrenamiento asertivo), de relajación (muscular) y de entrenamiento verbal.

Durante todo el proceso de intervención en los niños y su familia contamos con la colaboración de los tutores. Las orientaciones a los tutores van dirigidas fundamentalmente a que potencien la actividad lingüística de los niños, estimulándoles y reforzándoles los intentos expresivos. Cada quince días mantenemos reuniones, en ellas se comentan los progresos de los niños y se establecen conjuntamente cuáles son los pasos a seguir y las actividades a llevar a cabo en el contexto escolar e institucional. La actitud de los tutores y la implicación de los mismos fue esencial para generalizar y afianzar los avances que logramos con los niños.

\section{Conclusiones}

A lo largo del artículo hemos podido comprobar la necesidad de poner en marcha programas de intervención que incidan en la competencia personal, lingüística y social de menores que han sido objeto de situaciones de maltrato infantil. En estos niños es fundamental el desarrollo de habilidades o competencias que promuevan el funcionamiento social adaptativo, habilidades básicas para la interacción social que favorezcan la función pragmática del lenguaje (iniciar, mantener y terminar conversaciones, saludar, sonreír, expresar opiniones, sentimientos y emociones,...), habilidades para relacionarse con adultos y para la solución de problemas interpersonales (Edelman y Goldstein, 1981; Michelson, Sugai, Wood y Kazdin, 1987; Goldstein, Sprafkin, Gershaw y Klein, 1989; Weissberg, Caplan y Sivo, 1990; Mestre, Pérez-Delgado y Moltó, 1991; Monjas, 1993; Wolfe y Pierre, 1993; López, Apocada, Eceiza, Etxebarría, Fuentes y Ortiz, 1994; etc.).

Tal y como señalan Rowe, Cain, Hundleby y Keane (1990), Skinner (1992), Colton y Hellinckx (1993) y Fuertes y Fernández (1996), los centros de acogida han evolucionado de un planteamiento puramente asistencial a otro más educativo. Esto conlleva una mayor profesionalización de los técnicos, lo que supone un enorme beneficio para los menores. De ahí que internamiento deba tener un carácter formativo. No se trata de atender exclusivamente las necesidades básicas de los niños, sino también las repercusiones de éstos en las diferentes áreas del desarrollo (lingüística, social, cognitiva y motriz). 


\section{Referencias}

Aguado, G. (2000). Desarrollo de la Morfosintaxis en el Niño (T.S.A.) (3 ${ }^{\mathrm{a}}$ Ed.). Madrid: CEPE.

Aguinaga, G., Armentia, M. L., Fraile, A., Olangua, P. \& Uriz, N. (1990). Prueba de Lenguaje Oral de Navarra (P.L.O.N.). Madrid: TEA.

Arruabarrena, M.I., De Paúl, J. y Torrés, B. (1996). El maltrato infantil: detección, notificación, investigación y evaluación. Programa para la mejora del sistema de atención social a la infancia (SASI). Madrid: Ministerio de Asuntos Sociales.

Bousha, D.M. y Twentyman, C.T. (1984). Mother-child interaction style in abuse, neglect and control groups: naturalistic observations in the home. Journal of Abnormal Child Psychology, 93, 106-114.

Ciccietti, D y Carlson, V. (1989). Child maltreatment. Cambridge: Cambridge University Press.

Colton, M.J. y Hellinckx, W. (1993). Child care in the EC. Andershof: Arena.

Dodge, K.A., Bates, J.E. y Pettit, G.S (1994). Effect of physical maltreatment on the development of peer relations. Development and Psychopathology, 6, 43-55.

Edelman, E. M. y Goldstein, A.P. (1981). Moral education. En P. Goldstein, E.G. Carr, W.S. Davidson y P. Wehr (Eds.), In response to aggression. Nueva York: Pergamon.

Fuertes Zurita, J. y Fernández del Valle, J. (1996). Recursos residenciales para menores. En J. de Paúl y M $\mathrm{M}^{\mathrm{a}}$ I. Arruabarrena (Eds.), Manual de Protección Infantil. Barcelona: Masson.

Gaudin, J. M., Polansky, N.A., Kilpatrick, A.C. y Shilton, P. (1996). Family functioning in neglectful families. Child Abuse and Neglect, 20, 363-377.

Goldstein, A. P., Sprafkin, R.P., Gershaw, N.J. y Klein, P. (1989). Habilidades sociales y autocontrol en la adolescencia. Barcelona: Martínez Roca.

Goodglass, H. y Kaplan, E. (1996). Evaluación de la afasia y de trastornos relacionados (2a Ed.). Madrid: Médica Panamericana.

Kirk, S. A., McCarthy, J. J. y Kirk, W. D. (1968). Test Illinois de Aptitudes Psicolingüísticas (I.T.P.A.). Madrid: TEA.

López, F., Apocada, P., Eceiza, A., Etxebarría, I., Fuentes, M.J. y Ortiz, M.J. (1994). Conducta altruista. Estella: VD.

Martínez, A. y De Paúl, J. (1993). Maltrato y abandono en la infancia. Barcelona: Martínez Roca. 
McCarthy, D. (1972). Escalas McCarthy de Aptitudes y Psicomotricidad para niños (M.S.C.A.). Madrid: TEA.

Mestre, M.V., Pérez-Delgado, E. y Moltó, J. (1991). Los instrumentos de evaluación moral. En E. Pérez-Delgado y R. García-Ros (Eds.), La psicología del desarrollo moral. Madrid: Siglo XXI.

Michelson, L., Sugai, D.P., Wood, R.P. y Kazdin, A.E. (1987). Las habilidades sociales en las infancia. Barcelona: Martínez Roca.

Monjas, M.I. (1993). Programa de enseñanza de habilidades de interacción social para niños y niñas en edad escolar. Valladolid: M.I. Monjas.

Moreno, J. M. (2005). Estudio sobre las consecuencias del maltrato infantil en el desarrollo del lenguaje. Rev. Anales de Psicología, 21 (2), 224-230.

Moreno, J.M (2003). Estudio sobre las repercusiones lingüísticas del maltrato y abandono emocional infantil. Rev. Logopedia, Foniatría y Audiología, 23 (4), 211-222.

Puyuelo, M., Renom, J., Solanas, A. y Wiig, E. H. (2002). Batería de lenguaje objetiva y criterial Screening (BLOC-Screening). Barcelona: Masson.

Puyuelo, M., Wiig, E. H., Renom, J. y Solanas, A. (1998). Batería de Lenguaje Objetiva y Criterial (B.L.O.C.). Barcelona: Masson.

Rondal, J.A. (1999). El desarrollo del lenguaje. Barcelona: ISEP.

Rowe, J., Cain, H., Hundleby, M. y Keane, A. (1990). Child care now. Londres: BAAF.

Rutter, M. y Lord, C. (1986). Language disorders associated with psychiatric disturbance. En W. Yule y M. Rutter (Eds.), Language development and disorders. Londres: McKeith Press.

Skinner, A. (1992). Another kind of home. A review of residential child care. Edimburgo: HMSO.

Skuse, D. (1992). The relationship between deprivation, physical growth and the impaired development of language. En P. Flecher y D. Hall (Eds.), Specific speech and language disorders in children: correlates, characteristics and outcomes. Londres: Whurr.

Tizard, B., Cooperman, O., Joseph, A. y Tizard, J. (1972). Environmental effects on language development: a study of young children in long stay residential nurseries. Child Development, 43,337-358.

Urquiza, A.J. y Winn, C. (1994). Treatment for abused and negleted children: infancy to age 18. Washington: U.S. Department of Health \& Human Services Administration for Children and families. 
Wechsler, D. (1995). Escala de Inteligencia de Wechsler para niños Revisada (WISC-R). Madrid: TEA.

Weissberg, R. P., Caplan, M.Z. y Sivo, P.J. (1990). A new conceptual framework for establishing school-based social competence promotion programs. En L.A. Bond y B.E. Compas (Eds.), Primary prevention and promotion in the schools. Londres: Sage Publications.

Wolfe, D.A. y Pierre, L. (1993). El abuso y abandono en la infancia. En J. Ollendick y L. Hersen (Eds.), Psicopatología infantil. Barcelona: Martínez Roca. 
Juan Manuel Moreno Manso et al.

[Página en blanco por razones de paginación] 